УДК 331.101.262:331.5.316.324.8

\title{
СТРУКТУРНЫЕ СДВИГИ В НЕОИНДУСТРИАЛЬНОЙ МОДЕЛИ РАЗВИТИЯ ЧЕЛОВЕЧЕСКОГО КАПИТАЛА
}

\author{
Гузырь Владимир Васильевич1, \\ guzyr@tpu.ru \\ Потягайлов Сергей Витальевич1, \\ saviour.bowshot@mail.ru \\ Жаворонок Анастасия Валерьевна ${ }^{1}$, \\ zhavoronok@tpu.ru \\ Воробьева Екатерина Сергеевна², \\ ekaterina-vorob2015@yandex.ru \\ 1 Национальный исследовательский Томский политехнический университет, \\ Россия, 634050, г. Томск, пр. Ленина, 30 \\ 2 Приамурский государственный университет имени Шолом-Алейхема, \\ Россия, 679015, г. Биробиджан, ул. Широкая, 70а
}

Гузырь Владимир Васильевич, кандидат экономических наук, заместитель директора по развитию Школы базовой инженерной подготовки Национального исследовательского Томского политехнического университета.

Потягайлов Сергей Витальевич, соискатель ученой степени кандидата экономических наук Школы инженерного предпринимательства Национального исследовательского Томского политехнического университета.

Жаворонок Анастасия Валерьевна, старший преподаватель отделения социально-гуманитарных наук Школы базовой инженерной подготовки Национального исследовательского Томского политехнического университета.

Воробьева Екатерина Сергеевна, аспирант кафедры экономики, управления и финансового права Приамурского государственного университета имени Шолом-Алейхема, Россия, 679015, г. Биробиджан, ул. Широкая, 70а.

Актуальность исследования обусловлена проблемами развития социально значимых ключевых отраслей национальной экономики. Образующийся при попытках модернизащии существующих взаимосвязей разрыв приводит к закономерному дисбалансу между требованиями и возможностями реализации в рамках социально-экономических процессов. Эти процессы стимулируют развитие структурных сдвигов негативного характера внутри сложившейся модели рыночных взаимоотношений. Отсутствие корректировок последствий отрищательного структурного сдвига в лучшем случае приведет к стагнационным процессам в экономике, а в худшем - к устареванию материально-технической базы с последующим требованием восстановления или замещения недостающих элементов функционирования в том или ином технологическом укладе. Формирующееся проблемное поле ставит необходимость целеполагания в направлении создания комплексного подхода к решению двух взаимосвязанных проблем в рамках теории новой индустриализации: преодоление негативных структурных сдвигов в процессе развития новой индустриализации (шестой технологический уклад) с параллельным воспроизводством/эволюцией/использованием современного человеческого капитала и стимулирование его включенности в процесс инновационной модернизации индустриального комплекса. Человек как экономическая единица может выступить в качестве элемента, нивелирующего негативные структурные сдвиги за счет своей включенности с точки зрения производителя и потребителя товаров и услуг новой экономической формации. В резуль- 
тате проведенного исследования сформулированы ключевые инструменты воспроизводства и вовлечения человеческого капитала в существующие инновационные процессы.

Ключевые слова: Отрицательные структурные сдвиги, неоиндустриальный сдвиг, рынок человеческого капитала, инновации, новая индустриализация.

В современный период структурная устойчивость индустриально развитых экономик связана с выдвижением индустриальной базы на позицию определяющего фактора в условиях становления конкурентных преимуществ нового типа, основанных на знаниях, умениях и компетенциях людей, что формирует кардинальное изменение роли человеческого капитала в процессе индустриального развития экономики.

Изменение места и роли человека, превращение его интеллекта в ключевой фактор научно-технологического прогресса, усиление социализации экономических отношений объективизируют необходимость изучения процессов капитализации человеческого потенциала и выбора инструментов воспроизводства и стимулирования вовлечения человеческого капитала в научно-производственную сферу экономики. Сегодня данный процесс актуализировался в исследованиях И.Г. Миронова [1], Е.В. Смирнова [2], Е.В. Петрова [3], С.Д. Бодрунова [4, 5], О.П. Недоспасовой [6], Е.В. Неходы [7], Т.Л. Смирновой [8], Ю.В. Гунякова [9], А.В. Корицкого [10] и др. [11-16].

Следует отметить, что некоторые европейские страны пошли на установление устойчивости своих экономических систем через рассмотрение индустриальной базы как одного из ключевых факторов развития, применяя для этого научно-технические наработки и модернизацию человеческих ресурсов в качественном направлении. При этом человеческий капитал рассматривается с точки зрения высококвалифицированных кадров в качестве связующего звена для синхронного и устойчивого развития экономических структур в рамках шестого технологического уклада.

Создание качественно новых человеческих ресурсов возможно лишь при формировании необходимых условий их полноценной генерации, развития и востребованности. Данный процесс возможен при условии возникновения потребности научно-производственной сферы в качественно новых человеческих ресурсах. Такая необходимость может возникнуть в условиях становления подходов теории новой индустриализации в рамках национальной экономики, основанной на инновационном типе развития индустрии в целом. Новая индустриализация (неоиндустриализация) выступает теорией, направленной на попытку преодоления накопленных отрицательных структурных сдвигов за счет инновационных подходов к ведению индустриальных процессов. Новый подход к индустрии основан на генерации качественно новых продуктов и услуг с высокой долей интеллектуальной собственности, усилении роли человеческого капитала в данном процессе.

Инновационное развитие, воспроизводство человеческого капитала и становление новых технологических укладов неразрывно связаны. В подтверждение данной идеи воспользуемся точкой зрения Глазьева о том, что воспроизводство трудовых ресурсов (их создание и развитие) происходит на последнем завершающем воспроизводственном контуре формирующегося технологического уклада. Подготовка подобных человеческих ресурсов одновременно приводит к расширению технологического уклада и позволяет поддерживать в жизнеспособном состоянии его ядро, образованное революционным или эволюционным способом. Использование производителями инновационного продукта, сгенерированного с помощью новых технологических решений, в том числе работников с требуемой квалификацией, приводит к определению направлений стратегического развития и созданию новых лидирующих групп отраслей, описывающих условия реализации непрерывного социально-экономического развития. Образу- 
ющийся при этом новый технологический уклад формирует вероятные взаимосвязи между сопряженными производствами. Эти связи, также трактуемые как технологические совокупности, затрагивают весь цикл переработки ресурсов, производства, реализации, а также рассматривают тип непроизводственного потребления [17].

Изменение производственных взаимодействий, модернизации циклов производства, продуктов и услуг с применением новых современных подходов так или иначе приводит к переходу от индустриальных процессов к неоиндустриальным. Отличительной особенностью неоиндустриализации является всестороннее использование интеллектуального потенциала имеющихся человеческих ресурсов через модернизационные механизмы в отношении информационного поля, научно-исследовательской деятельности и сферы образования. Происходит формирование сферы интеллектуального производства, которая используется для создания новой добавленной стоимости в современном продукте или услуге. При этом неоиндустриация как идеология выступает в качестве макроэкономического процесса по внедрению комплекса прорывных технологических решений в производственный процесс.

Это приводит к следующим последствиям:

- роботизация процессов производства;

- синергия использования человеческих ресурсов и технических решений;

- формирование рынка инновационных продуктов и услуг;

- положительное изменение производительности труда;

- изменение принципов логистики и контроля качества в связи с особенностями конечного продукта с высокой долей интеллектуальной составляющей;

- увеличение потребности в высококвалифицированных кадрах;

- увеличение безработицы в результате невостребованности неквалифицированных кадров;

- увеличение разрыва уровня жизни между технологически развитыми и технологически отсталыми странами [18].

В свою очередь, в связи с протекающими глобальными национальными и мировыми процессами индустриального характера взаимосвязи внутри социальноэкономической системы могут носить двойственный характер производственного или профессионально-бытового характера, генерируя новые профессиональные объединения или социальные группы единых социально-экономических потребностей.

При этом поддержание полученных технологических совокупностей в рамках шестого технологического уклада, направленного на развитие инновационного продукта, является нетривиальной задачей. Создание и созидание данных новых взаимосвязей невозможно без носителей и генераторов интеллектуальной собственности, которая является весомой составляющей в новых продуктах и услугах. В связи с этим необходим обоснованный набор доверенных социально-экономических приёмов по вовлечению человеческого капитала в развивающуюся модель новой индустриализации.

Современные авторы предлагают для рассмотрения два основных этапа по генерации вовлеченности и развития человеческого капитала в условиях структурных сдвигов, направленных на развитие шестого технологического уклада.

Первый этап. Формирование и развитие инновационных компонент человеческого потенциала.

Второй этап. Создание института капитализации инновационных компонент, полученных за счет использования человеческого потенциала.

Первый этап подразумевает под собой создание базисных критериев развития современной личности: 
- креативное мышление;

- кросс-функциональность;

- разработка, обработка и интерпретация большого объема необходимой для решения задач информации;

- генерация и внедрение новых знаниеёмких решений в функционирующей (или формируемой) социально-экономической системе;

- адаптация и использование новых технологических решений в производственной или бытовой части.

Социальная политика, направленная на становление вектора непрерывного социально-экономического развития, должна прогнозировать необходимые качества нового человеческого капитала в рамках планируемых изменений в существующей национальной модели экономических взаимоотношений. Для этого необходимо сформировать ряд инструментов и мер для своевременного создания принципиально нового человеческого капитала, обладающего определенным рядом требуемых характеристик.

Реализация данной задачи может быть исполнена за счет использования следующих подходов и инструментов:

1. Совершенствование системы генерации и распространение знаний как образовательного процесса в рамках развития новой индустриализации.

1.1. Закрепление и развитие новых необходимых компетенций:

- предоставление человеку базисного набора необходимой информации с методологией для последующего самообучения: собственный поиск информации для усовершенствования полученных знаний. Данный подход должен включать в себя комплекс мер по обучению человека нахождению достоверной информации, ее восприятию и переосмыслению с дальнейшей генерацией инновационных идей. Без наличия базиса по ведению познавательной деятельности мы получим стагнацию в направлении саморазвития человеческих ресурсов;

- формирование инновационной культуры потребления, в том числе с применением появляющихся новых экономических теорий, таких как зеленая экономика, экономика счастья, экономика качеств, экономика «добра и зла» и других современных экономических течений, отождествляющих экономическую картину через призму человеческих качеств и потребностей [19];

- развитие новой модели потребления с точки зрения авторов данных теорий должно способствовать сокращению неблагоприятных воздействий создания (с последующим потреблением) товаров и услуг новой формации как на окружающую среду в целом, так и на каждого включенного индивида в частности;

- развитие умений анализа, воспроизводства и модернизации информационного поля и его элементов;

- генерация инновационных идей невозможна без формирования в индивиде подходов к самообучению, анализу полученной информации и способов создания нового интеллектуального продукта за счет применения ряда устоявшихся научных механизмов. В связи с этим у человека изначально должна быть развита способность анализировать получаемую им информацию из внешнего информационного поля. Только в таком случае, зная инструменты анализа и синтеза информации человек сможет работать с постоянно пополняющимся объемом интеллектуальных данных, которые, в свою очередь, могут носить неточный, недостоверный характер. Только 
проверка всех сопутствующих информации критериев и квалификация, а также база знаний генератора инновационной идеи (человеческого капитала) позволят создавать концептуально новые идеи и интеллектуальные продукты [20]. Реализация подобного комплекса действий (поиск, анализ, проверка и генерация новых идей) будет способствовать созданию конкурентоспособных специалистов в рамках новых инновационных рынков свободной конкуренции.

Умение данных человеческих ресурсов работать с имеющимся информационным полем позволит им самостоятельно повышать квалификацию по целому ряду вопросов, что, в свою очередь, частично снизит нагрузку работодателя по данному аспекту.

1.2. Введение образовательных стандартов для начального развития новаторских способностей: новаторство в рамках становления нового технологического уклада является одним из неотъемлемых требований развития социально-экономической модели, через генерацию и использование нового научного знания.

1.3. Развитие государственных образовательных программ по стандартам инновационного производства и сферы услуг.

Инструментом по введению новых стандартов к профессиональным навыкам может стать развитие в существующих образовательных организациях (университетах) новых образовательных услуг или модернизация существующих курсов. Модернизация должна проводиться с учетом экспертных оценок «профессий будущего» для проведения опережающей подготовкой качественно нового человеческого капитала для целей и задач экономики будущего. Для развития «профессий будущего» список данных направлений должен быть официально утвержден. Это позволит свободному рынку оценить возможные предпосылки к грядущим структурным сдвигам и занять открывающиеся ниши, необходимые для долгосрочного развития национальной экономики.

Уже в настоящее время в условиях смешанных переходных процессов становления новых технологических укладов можно наблюдать необходимость развития новых профессиональных направлений. Современные исследователи выделяют семь основных направлений развития таких специальностей (см. рисунок).



Рисунок. Центры генерации новых профессии, по мнению исследователей НИУ ВШЭ [21]

Figure. Centers for the generation of new professions, according to researchers at the Higher School of Economics [21] 
В исследовании отечественных авторов выделяются следующие возможные и уже применяемые на рынке труда профессии:

Менеджмент:

- цифровой маркетолог (разработчик интегрированных компаний по продвижению товаров и услуг с использованием новых цифровых каналов взаимодействия с аудиторией);

- эксперт в области науки, технологий и инноваций (разработчик инструментов научно-технологической политики, индикаторов оценки качественных и количественных характеристик для определения вклада производимых фирмой действий по достижению поставленных социально-экономических целей);

- менеджер по формированию впечатлений (сфера деятельности относится к контролю вопросов управления между компанией и клиентами, предполагает анализ клиентских проблем и нужд для создания позитивного эмоционального образа компании и предоставляемых ей услуг и товаров).

Общественные и гуманитарные науки:

- кросс-культурный психолог-консультант (исследователь социальнопсихологических проблем в сферах бизнеса, экономики образования и политики, проводящий соответствующие консультационные мероприятия по вопросам межнационального и кросс-культурного взаимодействия);

- юрист в сфере информационных технологий (консультант фирм по мероприятиям, связанным со становлением правил и принципов цифровой экономики);

- дата-журналист (сотрудник, способный создать текстовые документы на основе предоставленных ему достоверных данных и фактов);

- куратор мультимедийных выставок (разработчик и реализатор концепции проекта, решающий организационные и творческие вопросы);

- цифровой продюсер (управление сложными многоплатформенными медиапроектами с применением цифровых технологий);

- компьютерный лингвист (разработчик программ для обработки естественного языка: распознавание текста и речи, внедрение систем перевода, создание голосовых ассистентов, персональных помощников и программируемых ботов).

Информатика и бизнес-информатика:

- системный архитектор (руководитель проекта по построению архитектуры программно-аппаратных решений);

- системный программист (разработчик системного и базисного программного обеспечения, в том числе методов и инструментов моделирования и анализа информации);

- специалист по кибербезопасности (специалист по выявлению угроз информационной безопасности);

- консультант по электронному бизнесу (консультант по вопросам развития бизнеса в интернет-среде).

Прикладная математика и науки о данных:

- прикладной математик-исследователь (разработчик математических методов моделирования и анализа процессов, происходящих в высокотехнологичных областях промышленности);

- специалист по анализу данных (специалист по обработке и анализу большого массива данных структурированного или неструктурированного вида с помощью методов статистического анализа и/или построения математических моделей);

- биоинформатик (специалист, способный производить аналитику медикобиологических данных в отношении функций генов, расшифровку белкового состава, проведение генетической диагностики, конструирование лекарственных препаратов); 
- менеджер индивидуальных медицинских программ (специалист, разрабатывающий индивидуальные программы лечения и профилактики заболеваний).

Управление образованием: тьютор (консультант по вопросам выбора профессионального вектора развития личности как отдельных граждан, так и организационных структур).

Экономика и финансы:

- финансист-экономист (специалист, способный провести анализ финансовых показателей компании и внешних рынков с ведением прогнозирования социальноэкономического развития компании);

- финансовый аналитик (специалист по повышению эффективности рабочих процессов: оптимизация управления финансами, анализ и управление рисками, утверждение вектора инвестиционной деятельности, проведение качественных и количественных оценок экономической деятельности предприятия);

- финансовый инженер (специалист, занимающийся конструированием новых финансовых инструментов и продуктов с параллельным анализом финансовых рынков и тренда их развития);

- финансовый менеджер (аналитик в направлении контроля рисков компании, производящий контрольные мероприятия в отношении потребностей учреждения и привлечения дополнительного капитала, производит контроль-инвестиционной деятельности и анализ движения денежных средств).

Физика и электроника:

- специалист по управлению сетями квантовых коммуникаций (инженер, обладающий компетенциями по контролю функционирования и работоспособности создаваемых сетей квантовых коммуникаций);

- физик наноструктур и разработки наноматериалов (инженер, изучающий структуру и свойства новых современных материалов);

- инженер-исследователь в области наноэлектроники (инженер, разрабатывающий и внедряющий новые материалы и приборы в сфере электроники и наноэлектроники с применением знаний из области квантовой теории, физики твердого тела и нанотехнологий, осуществляющий проведение собственных научных исследований).

1.4. Внедрение гуманитарных дисциплин во все направления подготовки с целью формирования идеологии «нового потребления» у всех будущих специалистов во всех отраслях экономической жизни.

Ведение подобных курсов для будущих специалистов должно сформировать понимание принципов и целей новой индустриализации на всех этапах социальноэкономических взаимодействий через создание и внедрение знаний в рамках реализации концепции создания новых человеческих ресурсов как элементов инновационного процесса развития экономики. В теории это позволит минимизировать ряд барьеров для рынков современной продукции и услуг, а также способов их производства с закономерным формированием мультипликативного эффекта в отношении науки для обеспечения потребностей современного человека. Развитие теории с целью обеспечения персонализированной потребности связано с проблематикой перепроизводства определенного продукта индустриального сектора. Отечественными авторами отмечаются проблемы перенасыщения экономики продуктами тяжелой промышленности в девяностых годах прошлого века в рамках национальной социально-экономической системы, что плачевно сказалось на производстве товаров народного потребления [22].

Распространение идеи персонализированного спроса и конкурентоспособного предложения на открытых национальных и мировых рынках позволят активизировать заложенный потенциал нового человеческого капитала через использование когнитив- 
ных знаний научно-производственного характера в рамках его прикладного применения, для формирования предпосылок по созданию новых центров инновационного развития социально-экономических систем [23].

1.5. Использование общепринятого инструмента повышения квалификации или получения дополнительного профессионального образования для усовершенствования знаний и навыков имеющегося национального человеческого капитала.

Реализация данных направлений возможна как за счет собственных ресурсов конкретного индивида, так и общих социальных инвестиций в нуждающиеся в корректировке группы лиц. Результат достигается за счет формирования новой системы корпоративных институтов в условиях становления новой индустриализации с целью достижения систематической сбалансированности [24]. При наличии таких условий роста человеческих ресурсов мы имеем дело с локальной внешней средой для каждой отдельной персоны. Данная среда, в свою очередь, формирует стиль поведения человека через прививание ему нового корпоративного образа жизни в целях развития социально-экономической системы локальной фирмы или производства.

2. Необходимость увеличения социально-экономической активности национальных компаний. Сокращение социальных программ во времена социальных реформ национальной социально-экономической системы закономерно привело к нестабильности социальной инфраструктуры внутри действующих предприятий и фирм. Вариант по предотвращению стагнации социальной составляющей на предприятии может рассматриваться с позиции теории о национальном благосостоянии: необходимо обеспечить адресную поддержку молодым ученым и специализированным работникам, занятым в инновационной промышленности и сфере услуг вложения инвестиций в будущий человеческий капитал через инструменты стипендиального обеспечения аспирантов [25] с параллельным уменьшением налоговой нагрузки на население, а также использование альтернативных способов развития социально-экономической среды за счет реализации проектов с государственным и частным участием.

3. Дуализм социально-экономической природы экономического человека. При включении человека как неотъемлемого связующего звена в развитие экономических систем необходимо учитывать двойственность человеческих ресурсов в товарно-рыночных отношениях: реализация своих потребностей (как обычный потребитель) в продуктах и услугах существующей социально-экономической системы и способность создавать необходимые продукты и услуги остальным членам общества (как производитель). Из-за специфики формирования нового инновационного продукта в рамках новой индустриализации потребности и способность ее реализации формируют и компенсируют друг друга.

В рамках развития шестого технологического уклада качественный уровень способностей человеческого капитала очень сильно влияет на способность удовлетворения возрастающих потребностей в инновационной продукции и услугах общества в целом. В связи с этим необходимо своевременное и качественно новое создание и воспроизводство человеческого капитала, способного справиться с формируемыми потребностями внутри новой функционирующей институциональной сферы социально-экономических взаимодействий.

При этом новая социально-экономическая модель сконцентрирована на создании возможности удовлетворения потребностей персонализированного характера для каждого отдельного члена общества. Развитие общества направлено на достижение общей цели: удовлетворение всех уровней потребностей (по А. Маслоу) для каждого конкретного человека от низших до верхних уровней внутри существующей социально-экономической модели. Целью каждой личности внутри системы является максимизация развития физиче- 
ской, интеллектуальной и духовной составляющей с учетом теории оптимального набора «шведского стола» внутри каждого конкретного человека [26]. Драйвером же роста человеческого капитала внутри существующих домашних хозяйств должны стать персоналии, обладающие потребительской моделью с широкой направленностью, ориентированной на саморазвитие личности. Такой человеческий капитал отличается высоким уровнем образования, а величина доходов позволяет тратить на удовлетворение неотложных нужд только их треть, что свидетельствует о наличии возможности потребительского и инвестиционного выбора [27]. Условием качественной характеристики изменения приоритетов и направления структурных преобразований является формирование модели активного потребительского поведения как высшей социокультурной формы жизнедеятельности, включающей способность удовлетворять материальные потребности на достойном уровне, а также когнитивные и социальные потребности в условиях сформированных привычек «зеленого» или иного инновационного потребления.

4. Разработка инструментария ликвидации барьеров развития рынка. Становление принципов новой индустриализации через внедрение инновационного подхода в уже устоявшихся бизнес-схемах является нетривиальной задачей. Необходимо создать новые социально-экономические связи, объединяющие воедино инновационные процессы, конечную продукцию и потребительские ожидания. Для этого необходимо разработать ряд механизмов гарантируемой реализации первых партий инновационной продукции или услуг. Единственным способом для развития данного сценария, на взгляд авторов, является государственный целенаправленный заказ регионального или федерального значения.

5. Установление вектора государственной структурной политики на развитие шестого технологического уклада с привлечением человека. Все структурные сдвиги должны проводиться с жестким контролем государства для целей ликвидации конечных негативных структурных сдвигов со своевременным усилением влияния положительных структурных сдвигов. Данный процесс осуществляется через институциональные подходы в отношении социально направленных отраслей. При этом происходит выдвижение на ключевые позиции человеческого капитала как основного элемента структурных преобразований. Также, в связи с рассмотрением человека как важнейшего элемента развития социально-экономических систем, необходимо проводить ускоренную модернизацию отстающих на сегодняшний день социальных отраслей.

Отсутствие внимания к рассмотрению человеческих ресурсов как неотъемлемой движущей силы развития экономики уже привело к сокращению высокоинтеллектуальной деятельности на производстве и переходу к труду с низкой величиной добавленной стоимости.

\section{Выводы}

Результаты рассмотрения вопроса развития человеческого капитала как ключевого элемента структурных сдвигов в неоиндустриальной модели приводит нас к выводу о необходимости рассмотрения следующих структурных аспектов:

- совершенствование национальной образовательной системы для целей и задач процесса новой индустриализации;

- развитие непрерывного благосостояния человеческих ресурсов;

- реализация государственной поддержки инновационного производства;

- интенсификация процесса цифровизации отраслей социальной сферы.

Реализация первого аспекта по совершенствованию сложившихся принципов проведения образовательных мероприятий с целью создания необходимых человече- 
ских ресурсов для ускоренного развития шестого технологического уклада приведет к закономерному увеличению добавленной стоимости конечного результата труда за счет применения концептуально новых компетенций в рамках исполнения поставленных целей новым формирующимся человеческим капиталом. При этом полученная в ходе выполнения работ на рынке инновационная продукция, целью создания которой служит улучшение качества жизни населения, позволит реализовать потребности современного человека на концептуально новом уровне.

Именно стимулирование интеллектуальной составляющей через развитие человеческого капитала поспособствует повышению производительности труда, реализации творческих идей на производственном уровне, применению инновационного мышления в рамках выполнения поставленных задач, а также совершенствованию умения использовать неординарные способы решения сложных социально-экономических задач.

Влияние второго аспекта частично описано за счет институционной среды и находится на федеральном и/или мировом контроле. Суть его заключается в формировании условий для реализации непрерывного развития благосостояния общества и конкретно взятого индивида внутри состоявшейся социально-экономической модели. Критерием реализации выполнения данных задач может служить оценка достигнутого человеком уровня и качества жизни через объективную (качественную) и субъективную (персонализированную) оценку. При этом, влияя на негативные факторы в ходе подобных оценок, можно сформировать новую усовершенствованную модель активного потребительского поведения, противодействуя негативным факторам при становлении новых инновационных рынков продуктов и услуг.

Третий аспект связан с проблематикой развития инновационных технологий с позиции экономических издержек производства. Попытка ускорить процесс перехода на шестой технологический уклад заставляет некоторые компании тратить большое количество своих финансовых ресурсов на модернизацию производства при условии, что их продукция изначально будет пользоваться незначительным спросом на внутреннем рынке. В связи с этими проблемами вопрос поддержки нового инновационного рынка товаров и услуг (в области программных продуктов на территории России) частично находится под контролем институциональной среды и поддерживается, в том числе, через механизмы государственных закупок, направленных на защиту отечественного производителя. Это частично позволяет оказать посильную помощь производителям отечественной инновационной продукции, частично возмещая затраты на переоборудование и НИОКР через альтернативные непрямые схемы государственной поддержки.

Развитие четвертого аспекта напрямую затрагивает материально-техническое оснащение национальных систем коммуникационного характера. Цифровизация отраслей социальной сферы, по мнению авторов, должна послужить усилению социализации и адаптации всех социальных групп через их активное вовлечение в современный информационный этап социально-экономической системы новой индустриализации.

\section{СПИСОК ЛИТЕРАТУРЫ}

1. Миронова И.Г. Гуманизация экономического роста: сущность: автореф. дис. ... канд. экон. наук. Саратов, 2010. - 28 с.

2. Смирнова Е.В. Цели и факторы гуманизации экономического роста // Пространство экономики. URL: https://cyberleninka.ru/article/n/tseli-i-faktory-gumanizatsii-ekonomicheskogo-rosta (дата обращения 10.07.2021).

3. Петрова Е.В., Смирнова Е.В. Содержание и структура гуманизации экономического роста // Пространство экономики. URL: https://cyberleninka.ru/article/n/soderzhanie-i-struktura-gumanizatsiiekonomicheskogo-rosta (дата обращения 10.07.2021).

4. Бодрунов С.Д. К новому качеству материального производства: будущее России в евразийском пространстве // Экономическое возрождение России. - 2016. - № 3. - С. 118-123. 
5. Бодрунов С.Д. О некоторых вопросах эволюции экономико-социального устройства индустриального общества новой генерации // Экономическое возрождение России. - 2016. - № 3 (49). - С. 5-18.

6. Недоспасова О.П., Барышева Г.А., Таран Е.А. Многосубъектный подход к обеспечению благополучия: взгляд с позиций теории человеческого капитала. - Томск: Изд-во ТГУ, 2015. - 290 с.

7. Нехода Е.В. Ограничения теории человеческого капитала // Управление человеческими ресурсами основа развития инновационной экономики. - 2015. - № 6. - С. 183-190.

8. Смирнова Т.Л. Развитие рынка рабочей силы в условиях инновационно-технологической трансформации российской экономики: автореф. дис. ... д-ра экон. наук. - Томск, 2015. - 42 с.

9. Гуняков Ю.В., Подопригора В.Г. Человеческий капитал как фактор развития экономики // Социально-экономический и гуманитарный журнал Красноярского ГАУ. - 2015. - № 2. - С. 27-32.

10. Корицкий А.В. Велика ли отдача человеческого капитала в России? // ЭКО. - 2018. - № 2. - С. $35-47$.

11. Шестакова И.Г. Человеческий капитал как ресурс // XXI век: итоги прошлого и проблемы настоящего плюс. - 2014. - Т. 2. - № 2 (18). - С. 37-42.

12. Игошин А.Н., Черемухин А.Д. Методика оценки величины человеческого капитала сельскохозяйственных организаций на основе данных годовой бухгалтерской (финансовой) отчетности // Балтийский гуманитарный журнал. - 2014. - № 4 (9). - С. 167-171.

13. Линёв А.И. Формирование структуры человеческого капитала предприятия для целей учета и анализа // Карельский научный журнал. - 2016. - Т. 5. - № 3 (16). - С. 14-17.

14. Прихач А.Ю., Попова Н.В., Казымов Ф.А. Человеческий капитал и научно-технический прогресс: взаимовлияние и развитие // XXI век: итоги прошлого и проблемы настоящего плюс. $-2015 .-$ T. 2. № 6 (28). - С. 372-379.

15. Артемьев А.В., Аксенова Н.А. Роль новых форм и методов государственного управления в сохранении и развитии человеческого капитала как основы роста современной экономики // Актуальные проблемы экономики и права. - 2014. - № 1 (29). - С. 77-83.

16. Терзи Н.В. Конкурентоспособность рабочей силы как экономическая категория // XXI век: итоги прошлого и проблемы настоящего плюс. - 2015. - Т. 1. - № 1 (23). - С. 261-264.

17. Глазьев С. Рывок в будущее. Россия в новых технологическом и мирохозяйственном укладах. - М.: Книжный мир, 2018. - 768 с.

18. Побываев С.А., Толкачев С.А. Переход к неоиндустриализации России: повестка дня и анализ вариантов // ЭВP. URL: https://cyberleninka.ru/article/n/perehod-k-neoindustrializatsii-rossii-povestka-dnya-ianaliz-variantov (дата обращения 10.07.2021).

19. Корицкий А.В. Велика ли отдача человеческого капитала в России? // ЭКО. - 2018. - № 2. - С. $35-47$.

20. Тоффлер Э. Шок будущего. - М.: АСТ, 2002. - 557 с.

21. 25 профессий будущего, к которым готовит НИУ ВШЭ. URL: https://www.hse.ru/25professions/ (дата обращения 10.07.2021).

22. Куимов В.В., Толстой Д.А., Куимов А.О. Новая политехническая школа - методологические ориентиры и возможности // Евразийский союз ученых. - 2016. - № 26-1. - С. 49-54.

23. Федотова В.Г. Академическая и (или) постакадемическая наука? // Вопросы философии. - 2014. № $8 .-$ C. 44-54.

24. Каячев Г.Ф. Корпоративная социальная ответственность в стратегии российского бизнеса в образовательной сфере // Траектория реформирования российской экономики: материалы Международного экономического симпозиума, посвященного 50-летию экономического факультета ТГУ. - Томск: Изд-во ТГУ, 2014. - С. 257-261.

25. Об утверждении перечня специальностей научных работников технических и естественных отраслей наук, при подготовке диссертаций по которым аспирантам и докторантам федеральных государственных образовательных учреждений высшего профессионального образования, образовательных учреждений дополнительного профессионального образования и научных организаций установлены стипендии в размере 6000 рублей и 10000 рублей соответственно: приказ Минобрнауки РФ от 24.08.2012 № 654. URL: https://minjust.consultant.ru/documents/3487 (дата обращения 10.07.2021).

26. Смородинская Н.В. Глобализированная экономика: от иерархий к сетевому укладу. - М.: ИЭ РАН, 2015. - $344 \mathrm{c}$.

27. Человеческий капитал как фактор социально-экономического развития. Краткая версия доклада / И.В. Абанкина, Т.В. Абанкина, К.Р. Абанокова и др. // XVII Апр. междунар. науч. конф. по проблемам развития экономики и общества. - М.: ИД Высшей школы экономики, 2016. - 76 с.

Поступила 12.07.2021 г. 
UDC 331.101.262:331.5.316.324.8

\title{
STRUCTURAL SHIFTS IN THE NEO-INDUSTRIAL MODEL OF HUMAN CAPITAL DEVELOPMENT
}

\author{
Vladimir V. Guzyr ${ }^{1}$, \\ guzyr@tpu.ru \\ Sergey V. Potyagaylov 1 , \\ saviour.bowshot@mail.ru \\ Anastasia V. Zhavoronok ${ }^{1}$, \\ zhavoronok@tpu.ru \\ Ekaterina S. Vorobyova ${ }^{2}$, \\ ekaterina-vorob2015@yandex.ru \\ ${ }^{1}$ National Research Tomsk Polytechnic University, \\ 30, Lenin avenue, Tomsk, 364050, Russia \\ ${ }^{2}$ Sholom-Aleichem Priamursky State University, \\ 70a, Shirokaya street, Birobidzhan, 679015, Russia
}

Vladimir V. Guzyr, Cand. Sc., deputy director for strategic development, National Research Tomsk Polytechnic University.

Sergey V. Potyagaylov, applicant, National Research Tomsk Polytechnic University.

Anastasia V. Zhavoronok, lecturer, National Research Tomsk Polytechnic University.

Ekaterina S. Vorobyova, postgraduate student, Sholom-Aleichem Priamursky State University.

The relevance of the research topic is caused by the problems of development of socially significant key sectors of the national economy. The gap formed during attempts to modernize existing relationships leads to a natural imbalance between the requirements and the possibilities of implementation within the framework of socio-economic processes. These processes stimulate the development of negative structural changes within the existing model of market relations. The lack of adjustments to the consequences of a negative structural shift, at best, will lead to stagnant processes in the economy, and at worst - to obsolescence of the material and technical base, followed by the requirement to restore/replace the missing elements of functioning in a particular technological order. The emerging problem field puts the need for goal-setting in the direction of creating an integrated approach to solving two interrelated problems within the framework of the theory of new industrialization: overcoming negative structural shifts in the development of new industrialization (6 $6^{\text {th }}$ technological order) with parallel reproduction/development/use of modern human capital and stimulation its involvement in innovative modernization of the industrial complex. A person as an economic unit can act as an element that neutralizes negative structural changes due to his involvement, both from the point of view of the producer and from the point of view of the consumer of goods and services of the new economic formation. As a result of the study, the key tools for reproduction and involvement of human capital in existing innovation processes have been formulated.

Key words: Negative structural shifts, neo-industrial shift, human capital market, innovation, new industrialization.

\section{REFERENCES}

1. Mironova I.G. Gumanizatsiya ekonomicheskogo rosta: sushchnost. Avtoref. Dis. Kand. nauk [Humanization of economic growth: essence. Cand. Diss. Abstract]. Saratov, 2010. 28 p. 
2. Smirnova E.V. Tseli i faktory gumanizatsii ekonomicheskogo rosta [Goals and factors of humanization of economic growth]. Prostranstvo ekonomiki. Available at: https://cyberleninka.ru/article/n/tseli-i-faktorygumanizatsii-ekonomicheskogo-rosta (accessed 10 July 2021).

3. Petrova E.V., Smirnova E.V. Soderzhanie i struktura gumanizatsii ekonomicheskogo rosta [The content and structure of humanization of economic growth]. Prostranstvo ekonomiki. Available at: https://cyberleninka.ru/article/n/soderzhanie-i-struktura-gumanizatsii-ekonomicheskogo-rosta (accessed 10 July 2021).

4. Bodrunov S.D. K novomu kachestvu materialnogo proizvodstva: budushchee Rossii v evraziyskom prostranstve [Towards a new quality of material production: the future of Russia in the Eurasian space]. Ekonomicheskoe vozrozhdenie Rossii, 2016, no. 3, pp. 118-123.

5. Bodrunov S.D. O nekotorykh voprosakh evolyutsii ekonomiko-sotsialnogo ustroystva industrialnogo obshchestva novoy generatsii [On some issues of the evolution of the economic and social structure of a new generation of industrial society]. Ekonomicheskoe vozrozhdenie Rossii, 2016, no. 3 (49), pp. 5-18.

6. Nedospasova O.P., Barysheva G.A., Taran E.A. Mnogosubektny podkhod k obespecheniyu blagopoluchiya: vzglyad s pozitsiy teorii chelovecheskogo kapitala [A multi-subject approach to ensuring well-being: a view from the perspective of the theory of human capital]. Tomsk, TSU Publ., 2015. $290 \mathrm{p}$.

7. Nekhoda E.V. Ogranicheniya teorii chelovecheskogo kapitala [Limitations of the theory of human capital]. Upravlenie chelovecheskimi resursami - osnova razvitiya innovatsionnoy ekonomiki, 2015, no. 6, pp. 183-190.

8. Smirnova T.L. Razvitie rynka rabochey sily v usloviyakh innovatsionno-tekhnologicheskoy transformatsii rossiyskoy ekonomiki. Avtoreferat Dis. Kand. nauk [The development of the labor market in the context of the innovative and technological transformation of the Russian economy. Cand. Diss. Abstract] Tomsk, 2015. 42 p.

9. Gunyakov Yu.V., Podoprigora V.G. Chelovecheskiy kapital kak faktor razvitiya ekonomiki [Human capital as a factor of economic development]. Sotsialno-ekonomicheskiy i gumanitarny zhurnal Krasnoyarskogo $G A U, 2015$, no. 2, pp. 27-32.

10. Koritskiy A.V. Velika li otdacha chelovecheskogo kapitala v Rossii? [Is the return on human capital great in Russia?]. EKO, 2018, no. 2, pp. 35-47.

11. Shestakova I.G. Chelovecheskiy kapital kak resurs [Human capital as a resource]. XXI vek: itogi proshlogo $i$ problemy nastoyashchego plyus, 2014, vol. 2, no. 2 (18), pp. 37-42.

12. Igoshin A.N., Cheremukhin A.D. Metodika otsenki velichiny chelovecheskogo kapitala selskokhozyaystvennykh organizatsiy na osnove dannykh godovoy bukhgalterskoy (finansovoy) otchetnosti [Methodology for assessing the value of the human capital of agricultural organizations based on the data of the annual accounting (financial) statements]. Baltiyskiy gumanitarnyy zhurnal, 2014, no. 4 (9), pp. 167-171.

13. Linov A.I. Formirovanie struktury chelovecheskogo kapitala predpriyatiya dlya tseley ucheta $\mathrm{i}$ analiza [Formation of the structure of the human capital of the enterprise for the purposes of accounting and analysis]. Karelskiy nauchny zhurnal, 2016, vol. 5, no. 3 (16), pp. 14-17.

14. Prikhach A.Yu., Popova N.V., Kazymov F.A. Chelovecheskiy kapital i nauchno-tekhnicheskiy progress: vzaimovliyanie i razvitie [Human capital and scientific and technological progress: mutual influence and development]. XXI vek: itogi proshlogo i problemy nastoyashchego plyus, 2015, vol. 2, no. 6 (28), pp. 372-379.

15. Artemev A.V., Aksenova N.A. Rol novykh form i metodov gosudarstvennogo upravleniya v sokhranenii i razvitii chelovecheskogo kapitala kak osnovy rosta sovremennoy ekonomiki [The role of new forms and methods of public administration in the preservation and development of human capital as the basis for the growth of the modern economy]. Aktualnye problemy ekonomiki i prava, 2014, no. 1 (29), pp. 77-83.

16. Terzi N.V. Konkurentosposobnost rabochey sily kak ekonomicheskaya kategoriya [Labor force competitiveness as an economic category]. XXI vek: itogi proshlogo i problemy nastoyashchego plyus, 2015, vol. 1, no. 1 (23), pp. 261-264.

17. Glazyev S. Ryvok $v$ budushchee. Rossiya v novykh tekhnologicheskom i mirokhozyaystvennom ukladakh [Leap into the future. Russia in new technological and world economic structures]. Moscow, Knizhny mir Publ., 2018. 768 p.

18. Pobyvaev S.A., Tolkachev S.A. Perekhod k neoindustrializatsii Rossii: povestka dnya i analiz variantov [Transition to neo-industrialization of Russia: agenda and analysis of options]. EVR. Available at: https://cyberleninka.ru/article/n/perehod-k-neoindustrializatsii-rossii-povestka-dnya-i-analiz-variantov (accessed 10 July 2021).

19. Koritskiy A.V. Velika li otdacha chelovecheskogo kapitala v Rossii? [Is the return on human capital great in Russia?]. EKO, 2018, no. 2, pp. 35-47.

20. Toffler E. Shok budushchego [Shock of the future]. Moscow, AST Publ., 2002. 557 p.

21. 25 professiy budushchego, $k$ kotorym gotovit NIU VShE [25 professions of the future for which NRU HSE / NRU HSE prepares]. Available at: https://www.hse.ru/25professions/ (accessed 10 July 2021). 
22. Kuimov V.V., Tolstoy D.A., Kuimov A.O. Novaya politekhnicheskaya shkola - metodologicheskie orientiry i vozmozhnosti [New polytechnic school - methodological guidelines and opportunities]. Evraziyskiy soyuz uchenykh, 2016, no. 26-1, pp. 49-54.

23. Fedotova V.G. Akademicheskaya i (ili) postakademicheskaya nauka? [Academic and/or post-academic science?]. Voprosy filosofii, 2014, no. 8, pp. 44-54.

24. Kayachev G.F. Korporativnaya sotsialnaya otvetstvennost v strategii rossiyskogo biznesa v obrazovatelnoy sfere [Corporate social responsibility in the strategy of Russian business in the educational sphere]. Materialy Mezhdunarodnogo ekonomicheskogo simpoziuma, posvyashchennogo 50-letiyu ekonomicheskogo fakulteta TGU. Traektoriya reformirovaniya rossiyskoy ekonomiki [Trajectory of reforming the Russian economy. Materials of the International Economic Symposium dedicated to the $50^{\text {th }}$ anniversary of the Faculty of Economics of TSU]. Tomsk, TSU Publ., 2014. pp. 257-261.

25. Ob utverzhdenii perechnya spetsialnostey nauchnykh rabotnikov tekhnicheskikh i estestvennykh otrasley nauk, pri podgotovke dissertatsiy po kotorym aspirantam i doktorantam federalnykh gosudarstvennykh obrazovatelnykh uchrezhdeniy vysshego professionalnogo obrazovaniya, obrazovatelnykh uchrezhdeniy dopolnitelnogo professionalnogo obrazovaniya $i$ nauchnykh organizatsiy ustanovleny stipendii $v$ razmere 6000 rubley i 10000 rubley sootvetstvenno [On approval of the list of specialties of scientific workers of technical and natural branches of science, in the preparation of dissertations for which graduate students and doctoral students of federal state educational institutions of higher professional education, educational institutions of additional vocational education and scientific organizations were granted scholarships in the amount of 6,000 rubles and 10,000 rubles, respectively]. Prikaz Minobrnauki RF ot 24.08.2012 no. 654 [Order of the Ministry of Education and Science of the Russian Federation of 08.24.2012 N 654]. Available at: https://minjust.consultant.ru/documents/3487 (accessed 10 July 2021).

26. Smorodinskaya N.V. Globalizirovannaya ekonomika: ot ierarkhiy k setevomu ukladu [The globalized economy: from hierarchies to a network structure]. Moscow, IE RAN Publ., 2015. 344 p.

27. Abankina I.V., Abankina T.V., Abanokova K.R. Chelovecheskiy kapital kak faktor sotsialnoekonomicheskogo razvitiya. Kratkaya versiya doklada [Human capital as a factor of socio-economic development. Brief version of the report]. XVII Aprelskaya mezhdunarodnaya nauchnaya konferentsiya po problemam razvitiya ekonomiki i obshchestva [XVII April International scientific conference on the problems of economic and social development]. Moscow, 19-22 April 2016. Moscow, Vysshaya shkola ekonomiki Publ. house, 2016. 76 p.

Received: 12 July 2021. 